\title{
Retracing Hotbeds of the 1918-19 Influenza Pandemic. Spatial Differences in Seasonal Excess Mortality in the Netherlands
}

By Rick J. Mourits, Ruben Schalk, Albert Meroño-Peñuela, Joe Raad, Auke Rijpma, Bram van den Hout and Richard L. Zijdeman

To cite this article: Mourits, R. J., Schalk, R., Meroño-Peñuela, A., Raad, J., Rijpma, A., van den Hout, B., \& Zijdeman, R. L. (2021). Retracing Hotbeds of the 1918-19 Influenza Pandemic. Spatial Differences in Seasonal Excess Mortality in the Netherlands. Historical Life Course Studies, 10, 145-150. https://doi.org/10.51964/hlcs9584

\section{HISTORICAL LIFE COURSE STUDIES}

Not Like Everybody Else.

Essays in Honor of Kees Mandemakers

VOLUME 10, SPECIAL ISSUE 3

2021

GUEST EDITORS

Hilde Bras

Jan Kok

Richard L. Zijdeman

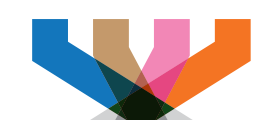




\section{HISTORICAL LIFE COURSE STUDIES}

Historical Life Course Studies is the electronic journal of the European Historical Population Samples Network (EHPSNet). The journal is the primary publishing outlet for research involved in the conversion of existing European and nonEuropean large historical demographic databases into a common format, the Intermediate Data Structure, and for studies based on these databases. The journal publishes both methodological and substantive research articles.

\section{Methodological Articles}

This section includes methodological articles that describe all forms of data handling involving large historical databases, including extensive descriptions of new or existing databases, syntax, algorithms and extraction programs. Authors are encouraged to share their syntaxes, applications and other forms of software presented in their article, if pertinent, on the openjournals website.

\section{Research articles}

This section includes substantive articles reporting the results of comparative longitudinal studies that are demographic and historical in nature, and that are based on micro-data from large historical databases.

Historical Life Course Studies is a no-fee double-blind, peer-reviewed open-access journal supported by the European Science Foundation (ESF, http://www.esf.org), the Scientific Research Network of Historical Demography (FWO Flanders, http://www.historicaldemography.be) and the International Institute of Social History Amsterdam (IISH, http://socialhistory.org/). Manuscripts are reviewed by the editors, members of the editorial and scientific boards, and by external reviewers. All journal content is freely available on the internet at https://openjournals.nl/index.php/hlcs.

\section{Co-Editors-In-Chief:}

Paul Puschmann (Radboud University) \& Luciana Quaranta (Lund University)

hislives@kuleuven.be

The European Science Foundation (ESF) provides a platform for its Member Organisations to advance science and explore new directions for research at the European level. Established in 1974 as an independent non-governmental organisation, the ESF currently serves 78 Member Organisations across 30 countries. EHPS-Net is an ESF Research Networking Programme.

The European Historical Population Samples Network (EHPS-net) brings together scholars to create a common format for databases containing non-aggregated information on persons, families and households. The aim is to form an integrated and joint interface between many European and non-European databases to stimulate comparative research on the micro-level.

Visit: http://www.ehps-net.eu.
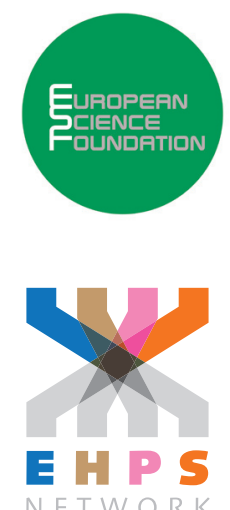


\title{
Retracing Hotbeds of the 1918-19 Influenza Pandemic Spatial Differences in Seasonal Excess Mortality in the Netherlands
}

\author{
Rick J. Mourits \\ Utrecht University \& International Institute of Social History, \\ Ruben Schalk \\ Amsterdam \& Radboud University Nijmegen \\ Albert Meroño-Peñuela \\ Utrecht University \\ Joe Raad \\ Auke Rijpma \\ Bram van den Hout \\ Richard L. Zijdeman \\ King's College London \\ VU Amsterdam \\ Utrecht University \& International Institute of Social History, \\ Amsterdam \\ International Institute of Social History, Amsterdam \\ International Institute of Social History, Amsterdam \& University of \\ Stirling
}

\section{ABSTRACT}

A century ago, the 1918-19 influenza pandemic swept across the globe, taking the lives of over 50 million people. We use data from the Dutch civil registry to show which regions in the Netherlands were most affected by the 1918-19 pandemic. We do so for the entire 1918 year as well as the first, second, and third wave that hit the Netherlands in summer 1918, autumn 1918, and winter 1919. Our analyses show that excess mortality was highest in Oost-Brabant, Zuid-Limburg, Noord-Holland, and Drenthe, Groningen, and Overijssel, whereas excess mortality was low in Zuid-Beveland, the Utrechtse Heuvelrug, and the Achterhoek. Furthermore, neighboring municipalities resembled one another in how severely they were affected, but only for the second wave that hit the Netherlands in autumn 1918. This non-random spatial distribution of excess mortality in autumn 1918 suggests that regional differences affected the spread of the disease.

Keywords: Mortality, Pandemic, Influenza, 1918-19 Influenza pandemic, Spanish flu, Spatial demography, Spatial clustering

e-ISSN: $\quad$ 2352-6343

DOI article: $\quad$ https://doi.org/10.51964/hlcs9584

The article can be downloaded from here.

(C) 2021, Mourits, Schalk, Meroño-Peñuela, Raad, Rijpma, van den Hout, Zijdeman

This open-access work is licensed under a Creative Commons Attribution 4.0 International License, which permits use, reproduction \& distribution in any medium for non-commercial purposes, provided the original author(s) and source are given credit. See http://creativecommons.org/licenses/. 


\section{INTRODUCTION}

In the summer of 1918, an influenza pandemic swept across the globe. Initially, outbreaks were relatively mild, but by fall, mortality surged as uncomplicated influenza infections rapidly progressed into fatal pneumonia. When the pandemic finally subsided in 1919, the 'Spanish' influenza pandemic had taken over 50 million lives worldwide (Taubenberger \& Morens, 2006). A century later, it is still not fully understood how the 1918-19 pandemic found its victims. We have a good understanding of which countries were affected by the disease and how the outbreak spread over the globe (Ansart et al., 2009; Patterson \& Pyle, 1991; Taubenberger \& Morens, 2006). However, we know surprisingly little about how the influenza outbreak spread within countries and whom the influenza outbreaks affected. Using data from the Dutch civil registry, we are now able to explore how the 1918-19 influenza outbreak spread throughout the Netherlands.

In this paper, we explore quarterly differences in excess mortality between municipalities in 1918 and 1919 to determine how the Spanish flu spread through the Netherlands. Diseases do not infect individuals randomly, but are passed on from one person to another. In this chain of transmission, resistance and avoidance generally play a very important role (Johansson, 2000). There is evidence that higher incomes associated with lower mortality, which is generally seen as a sign that welfare and nourishment protect against disease. However, recent studies have shown that it was those who could afford to distance themselves from the disease that were least affected were least likely to die from it. More specifically, the 1918 pandemic was deadlier to those who had smaller houses, lived in the slums, were illiterate, or did not work on the land, indicating that the best defense against the disease was to stay out of its way (Bengtsson, Dribe, \& Eriksson, 2018; Grantz et al., 2016; Mamelund, 2006). Here, we ask which regions in the Netherlands had exceptionally high or low excess mortality during the 1918-19 influenza pandemic to better understand how the virus spread between towns. We begin by showing how the Dutch civil registry can be used to study excess mortality (sections 2-3). After describing regional patterns in excess mortality (Section 4), we close with a discussion of the observed patterns and the potential of the civil registry data for further research.

We use digitized death certificates from the Dutch civil registry to study excess mortality in 1918-19. ${ }^{1}$ The Dutch civil registry was introduced in 1811 and well-established by 1918, so that the registration of deaths was common practice. Moreover, death certificates were made in duplicate, controlled by local judiciaries, and stored at separate locations, which ensured safekeeping for future generations (Mourits, van Dijk, \& Mandemakers, 2020). Besides the date of death, the digitized death records list the name, age, place of residence, and (sometimes) occupation of the deceased as well as information on the next of kin. The availability of the death date and place of residence makes it possible to study local deviations from the nationwide trend. For each municipality, baseline mortality was established using the average mortality between 1910 and 1917, excluding 1914 as the Netherlands took in 1 million Belgian refugees that year. ${ }^{2}$ The excess mortality rate is then calculated by subtracting the baseline mortality from the 1918 mortality rate and subsequently dividing it by the baseline mortality (see below). Local excess mortality rates are estimated for the entire year 1918 as well as also for the months when the waves of the influenza pandemic swept over the world: July-September 1918, October-December 1918, and January-March 1919. To our knowledge, this is the first time that quarterly excess mortality rates of the 1918-19 pandemic can be studied in such detail on a national scale.

$$
\text { Excess mortality rate }=\frac{\text { Mortality } 1918-\text { Baseline mortality }}{\text { Baseline mortality }}
$$

$1 \quad$ We use the death certificates hosted by openarchives (https://www.openarch.nl/overview/?slice1=sources). The source data is the same as used by the LINKS project and WieWasWie.

2 The Netherlands remained neutral in the First World War. However, in 1914 the southern provinces Limburg, Noord-Brabant, and Zeeland took in 1 million Belgian refugees, most of whom fled the siege of Antwerpen. Over $90 \%$ of these refugees returned to Belgium within a year's time, where they were forced to stay as the German's closed the border with a lethal electric fence, which came to be known as the 'wire of death'. The 100,000 remaining refugees were spread over the Netherlands and stayed until the end of the war. As the Dutch population was just over 6 million people, local mortality numbers are likely unreliable for many municipalities in 1914. Therefore, we opted to exclude 1914 from the benchmark. 
Regional differences in excess mortality due to the 1918-19 influenza pandemic are studied using historical maps of the Netherlands (Boonstra, 2007). Excess mortality is plotted on shapefiles developed with cut-offs determined by quintiles, so that regions with extremely low or high excess mortality during the 1918-19 influenza pandemic become more easily discernable. In order to determine whether we are looking at an actual spatial pattern, and not random noise, the degree to which the excess mortality rates in neighboring municipalities resemble one another is estimated with the Moran's I coefficient for spatial autocorrelation. To calculate the Moran's I, three different neighborhood matrices were constructed: 1) with all direct neighbors, 2) with all neighbors within a $10 \mathrm{~km}$ radius, and 3 ) with the three closest municipalities. ${ }^{3}$

\section{DATA QUALITY}

Data from the Dutch civil registry is being indexed by Dutch archives. Death certificates have been indexed for most Dutch municipalities and the data cleaning — for example, deduplication and standardization is mostly finished. To verify the quality of our data, we compare aggregated annual mortality information from the death registry with aggregated mortality information from the Historische Dataset Nederlandse Gemeentes [Historical Dataset Dutch Municipalities], or HDNG in short (Boonstra, Beekink, Engelen, \& Knippenberg, 2003; Boonstra, 2020). The HDNG mortality data is based on the Gemeentelijke Demografische Documentatie, which was published by Statistics Netherlands (CBS). Exact indications of the data quality in the HDNG are unavailable, but are thought to be at least a good approximation of the number of deceased per municipality.

Panel A of Figure 1 shows how annual excess mortality was distributed according to the HDNG for all of 1918. In a normal year, these findings are random, as - on average - no excess mortality took place. However, in nearly all municipalities mortality rates were higher for 1918 than in other years. Municipalities in dark red are municipalities that were hit the hardest by the pandemic and had excess mortality rates above the national average, whereas dark green municipalities had excess mortality rates that were significantly below average. When we only include the municipalities for whom death information is available from the death certificates data, the map remains practically the same, as shown in panel $B$. This indicates that we do not introduce bias in this subset of municipalities. These findings from the HDNG are very similar to the findings from the civil registry shown in panel $\mathrm{C}$, which shows that the civil registry data is suitable for studying the 1918-19 influenza outbreak in the Netherlands in more detail.

\section{REGIONAL DIFFERENCES}

Panel A-C in Figure 1 all show the excess mortality rates for 1918. In the Netherlands, there was especially high excess mortality in in Oost-Brabant, Zuid-Limburg, Noord-Holland, and Drenthe, Groningen, and Overijssel. On the other hand, excess mortality was low in Zuid-Beveland, the Utrechtse Heuvelrug, and the Achterhoek. The existence of regions with high excess mortality and regions with low excess mortality is not coincidental, as the Moran's I indicates that neighboring municipalities resembled one another. The Moran's I was 0.09-0.10 with $p<0.001$ for the map in panel B based on the HDNG and 0.08-0.09 with $p<0.001$ for the map in panel $C$ based on the civil registry data. These results clearly show that excess mortality was not randomly spread over the Netherlands, but clustered spatially.

Panels D-F use data from the death certificates to show whether the spatial pattern of 1918 excess mortality emerged during the first, second, and third wave of the 1918-19 influenza pandemic. These waves hit the Netherlands in the summer of 1918 (Q3), autumn of 1918 (Q4), and winter of 1919 (Q1), respectively. The maps in panel $D$ and $F$ clearly show that there was no spatial clustering of mortality in the summer of 1918 and winter of 1919. In fact, the Moran's I for the summer of 1918 of 0.00-0.02 with a p-value between 0.150 and 0.388 and the Moran's I for the winter of 1919 of $0.03-0.04$ with a p-value between 0.014 and 0.170 indicate that the spatial distribution of excess mortality was completely random.

$3 \quad$ For islands in model 1, the three closest municipalities were selected. 
Spatial clustering of excess mortality did occur during the autumn of 1918 . The Moran's I was $0.21-0.22$ with a $p$-value $<0.001$. The spatial pattern that we see in the autumn of 1918 strongly resembles the excess mortality rate for the entire year, although we now also see that the high-mortality cluster in Noord-Holland is less pronounced, whereas the high-mortality in Overijssel is more pronounced. This indicates that the spatial clustering of excess mortality in 1918 was solely dependent on an even more pronounced spatial pattern of excess mortality during the infamous second wave of the 1918-19 influenza pandemic. ${ }^{4}$

Figure $1 \quad$ Excess mortality in the Netherlands, 1918

A

Excess mortality 1918 HDNG percentage per municipality, no data selections

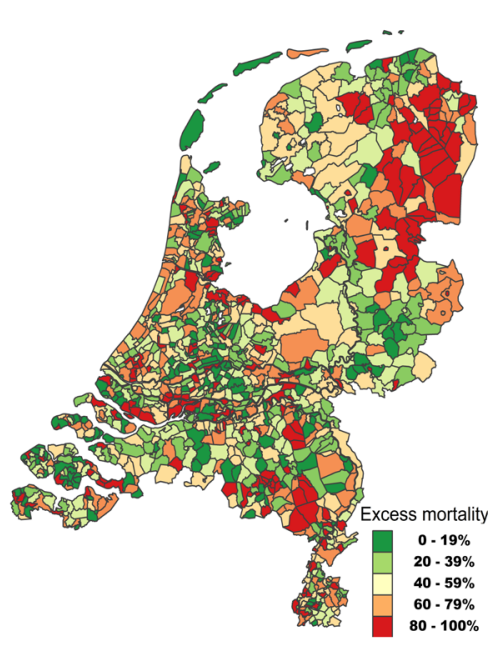

D

Excess mortality 1918 civil registry percentage per municipality July - September

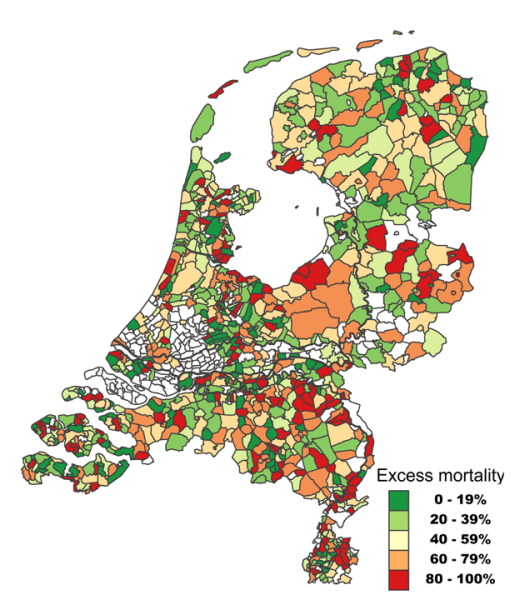

B

Excess mortality 1918 HDNG percentage per municipality, without missing data in civil registry

\section{Cxcess mortality 1918 civil registry percentage per municipality}
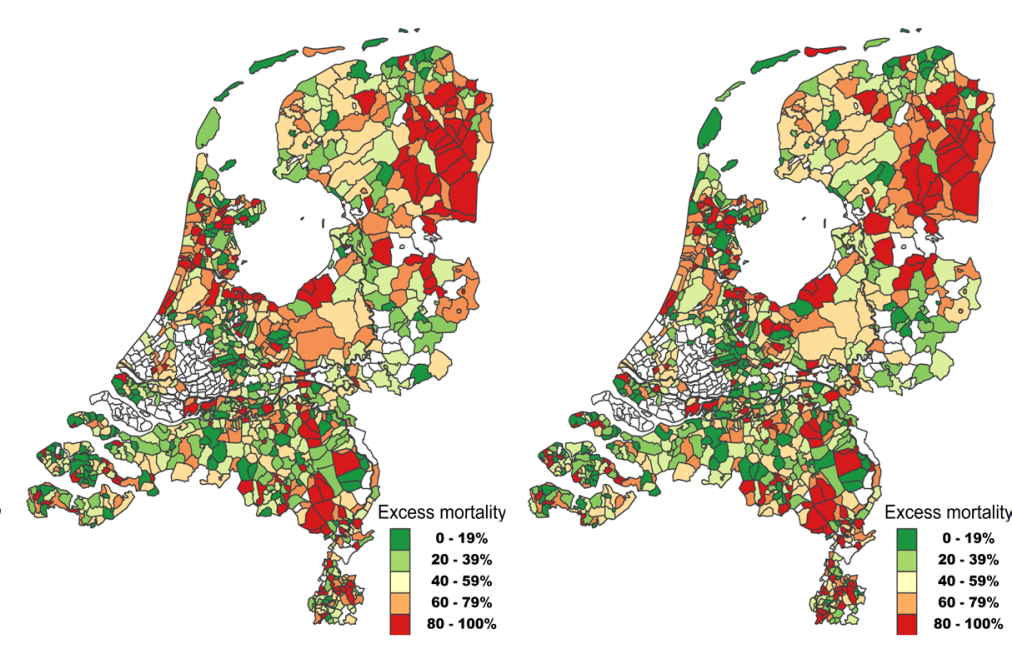

E Excess mortality 1918 civil registry
percentage per municipality October - December

\section{$\mathbf{F}$ \\ Excess mortality 1919 civil registry percentage per municipality January - March}
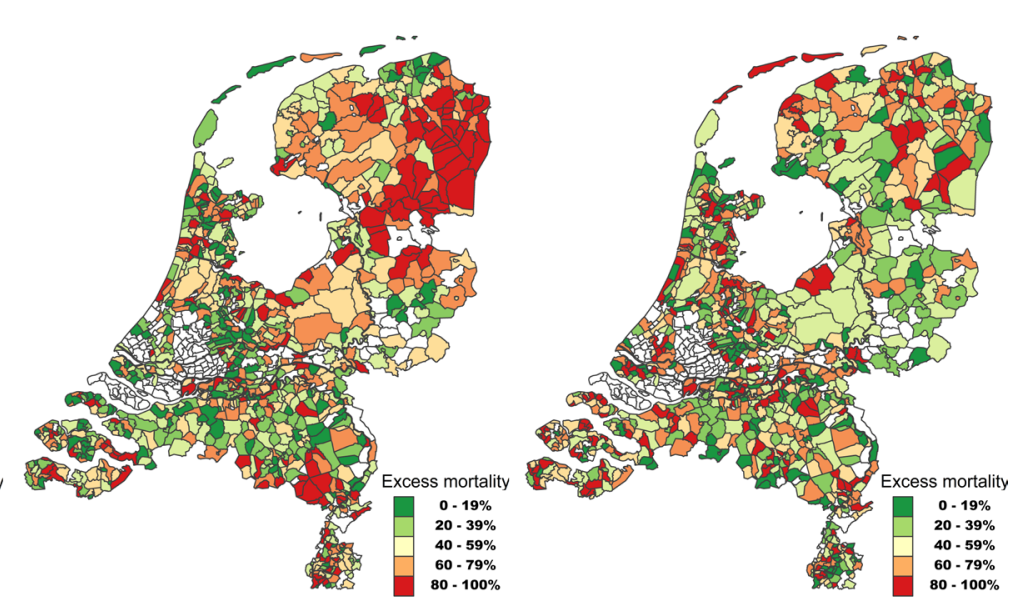

In this article, we reconstructed the spatial and temporal mortality patterns of the 1918-19 influenza outbreak in the Netherlands, using death certificates from the civil registry. Recorded on an individual rather than a regional or national level — as most mortality data — this dataset can significantly enrich historical

$4 \quad$ For more visualizations of the epidemic, as well as deaths per municipality, age group, or occupation, see the online datastory at https://stories.datalegend.net/spanishFluNetherlands. 
research, for instance by examining which social groups were affected by the 1918-19 epidemic to a greater degree. Before moving on to such studies, however, we first tried to establish if these data are of sufficient quality to do so. The comparison with the Historische Dataset Nederlandse Gemeentes [Historical Dataset Dutch Municipalities] confirms this. On a municipal level the results between the civil registry dataset and the HDNG are nearly identical. The spatial distribution of excess mortality in 1918 is the same across both datasets with clusters of high excess mortality in Oost-Brabant, Zuid-Limburg, Noord-Holland, and Drenthe, Groningen, and Overijssel and low excess mortality in Zuid-Beveland, the Utrechtse Heuvelrug, and the Achterhoek.

The data from the civil registry shows that the spatial clustering of excess mortality only occurred in autumn 1918. Apparently, the mortality peaks caused by the first and third wave in the summer of 1918 and winter of 1919 were too small to cause spatial clusters of excess mortality. The non-random spatial distribution of excess mortality in autumn 1918 suggests that other factors may have affected the spread of the disease. Based on research on local differences in Spanish flu mortality one would assume that increased social contact and environmental conditions make diseases more likely to spread in one context than the other. Because differences in economic activity and disease environments were very large in the early 20th century, this would mean that specific regions were hit harder than others. Centers of trade and industry were perhaps more likely to be exposed to the disease, as people travelling out and about might have been ideal vectors of the disease. Densely populated and humid environments might have been more suspect to rapid outbreaks, as these places were already known to be excellent breeding grounds for pathogens. However, our analyses show that the 1918-19 influenza outbreak was most severe in the northeastern part of the Netherlands that was rural, sparsely populated, and relatively dry due to the sandy soils.

Although local studies have shown that income hardly determined which inhabitants of a town were affected, poverty might have determined which regions were hit hardest. This would mean that increased vulnerability to the disease, rather than increased exposure, determined where excess mortality during the 1918-19 influenza outbreak was highest. Poverty might have led to undernourishment, making whole populations more vulnerable and less likely to recover from a wide range of infectious diseases (Rotberg \& Rabb, 1985). However, one needs to wonder whether extra nourishment could protect against severe inflammation and build-up of fluids in the lungs, as most deaths during the 1918-19 influenza outbreak were caused by proinflammatory responses and secondary infections to damaged lung tissue (Taubenberger \& Morens, 2006). A likely scenario is that high local levels of tuberculosis had already damaged the lung tissue of the local populace, so that the local populace was more vulnerable to secondary lung infections. Tuberculosis-related mortality was high in the northeast of the country, which was to a large extent caused by undernutrition (Janssens \& van Dongen, 2018). Such a scenario would be in line with findings from the United States, where severe air pollution from the coal industry coincided with higher excess mortality rates during the 1918-19 influenza outbreaks (Clay, Lewis, \& Severnini, 2018). In other words, poverty-related decreased resistance to infectious diseases as well as environmental factors that lead to damaged lung tissue, such as disease environments and pollution, should be considered as explanations for regional differences in excess mortality during the 1918-19 influenza pandemic.

Where the 1918-19 influenza pandemic struck and whom got affected probably depended on two different mechanisms. Nevertheless, earlier studies have shown that social isolation, even when unintended, was the only remedy against the Spanish flu on the individual level. Therefore, farmers were less likely to die during the 1918-19 influenza pandemic than the rest of the population, whereas those who lived in the slums were more likely to become infected (Bengtsson et al., 2018; Grantz et al., 2016; Mamelund, 2006). Similarly, those aged between 15 and 50 might have had a higher risk of exposure. There is wide-spread agreement that individuals between ages 15-50 were more likely to have complications and develop pneumonia (Taubenberger \& Morens, 2006), but these were also the people that travelled around and came into contact with most people. These people might have been the heralds of death, dying of the disease that they introduced to their own community. To properly understand how the 1918-19 influenza outbreak found its victims, both regional and individual characteristics need to be studied at the same time. Therefore, comparing the age and social composition of communities between regions that were least and most affected by the 1918-19 influenza outbreak can give us unprecedented insight into how the disease spread over the world.

The death certificates from the Dutch civil registry allows to do exactly this. Taking into account the age and occupational distribution might well explain why excess mortality in 1918 clustered in specific regions. A first glance at excess mortality by occupational groups, using the HISCO scheme (van Leeuwen \& Maas, 
2002), suggests that the working environment mattered. ${ }^{5}$ For example, travelling salespersons, office clerks, elementary teachers, and factory workers were hit relatively hard. Potentially personal contacts mattered, with salespersons travelling around and meeting people from different disease environments, and clerks, teachers and factory workers operating in closed, poorly ventilated buildings, and in the presence of many others. Vice versa, workers with potentially fewer co-workers, such as carpenters, and those working outside, such as crop workers and bricklayers, were affected by the flu to a much smaller degree. Yet even within these groups there were regional differences, suggesting more factors need to be considered. Combining micro-level observations of vital events of millions of individuals from the historical Dutch civil registry with other datasets such as the HDNG, provides an unprecedented opportunity to examine questions like these.

\section{REFERENCES}

Ansart, S., Pelat, C., Boelle, P. Y., Carrat, F., Flahault, A., \& Valleron, A. J. (2009). Mortality burden of the 1918-1919 influenza pandemic in Europe. Influenza and Other Respiratory Viruses, 3(3), 99-106. doi: 10.1111/j.1750-2659.2009.00080.x

Bengtsson, T., Dribe, M., \& Eriksson, B. (2018). Social class and excess mortality in Sweden during the 1918 influenza pandemic. American Journal of Epidemiology, 187(12), 2568-2576. doi: 10.1093/ aje/kwy151

Boonstra, O. (2007). NLGis shapefiles. DANS. doi: 10.17026/dans-xb9-t677

Boonstra, O. (2020). Historische Database Nederlandse Gemeenten, V3. IISH Data Collection. Retrieved from https://hdl.handle.net/10622/RPBVK4

Boonstra, O., Beekink, E., Engelen, T., \& Knippenberg, H. (2003). De Historische Databank Nederlandse Gemeenten (HDNG): Een nieuw hulpmiddel voor de bestudering van een samenleving in transformatie. In E. Beekink, O. Boonstra, T. Engelen, \& H. Knippenberg (Eds.): Nederland in verandering: Maatschappelijke veranderingen in kaart gebracht 1800-2000 (pp. 169-174). Amsterdam: Aksant Academic Publishers.

Clay, K., Lewis, J., \& Severnini, E. (2018). Pollution, infectious disease, and mortality: Evidence from the 1918 Spanish influenza pandemic. The Journal of Economic History, 78(4), 1179-1209. doi: 10.1017/ S002205071800058X

Grantz, K. H., Rane, M. S., Salje, H., Glass, G. E., Schachterle, S. E., \& Cummings, D. A. T. (2016). Disparities in influenza mortality and transmission related to sociodemographic factors within Chicago in the pandemic of 1918. Proceedings of the National Academy of Sciences of the United States of America, 113(48), 13839-13844. doi: 10.1073/pnas.1612838113

Janssens, A., \& van Dongen, E., (2018). A natural female disadvantage? Maternal mortality and the role of nutrition related causes of death in the Netherlands, 1875-1899. TSEG - Low Countries Journal of Social and Economic History, 14(4), 84-115. doi: 10.18352/tseg.988

Johansson, S. R. (2000). Macro and micro perspectives on mortality history. Historical Methods, 33(2), 59-72. doi: 10.1080/01615440009598950

Mamelund, S. E. (2006). A socially neutral disease? Individual social class, household wealth and mortality from Spanish influenza in two socially contrasting parishes in Kristiania 1918-19. Social Science and Medicine, 62(4), 923-940. doi: 10.1016/j.socscimed.2005.06.051

Mandemakers, K., Hornix, J., Mourits, R. J., Muurling, S., Boter, C., van Dijk, I. K., Maas, I., Van de Putte, B., Zijdeman, R. L., Lambert, P., van Leeuwen, M. H. D., van Poppel, F., \& Miles, A. (2020). HSN standardized, HISCO-coded and classified occupational titles, HSN release 2020.02. Amsterdam: IISG.

Mourits, R.J., Van Dijk, I. K., \& Mandemakers, K. (2020). From matched certificates to related persons: Building a dataset from LINKS-Zeeland. Historical Life Course Studies, 9, 49-68. Retrieved from https://hdl.handle.net/10622/23526343-2020-0006

Patterson, K. D., \& Pyle, G. F. (1991). The geography and mortality of the 1918 influenza pandemic. Bulletin of the History of Medicine, 65(1), 4-21. Retrieved from https://www.jstor.org/stable/44447656

Rotberg, R. I., \& Rabb, T. K. (1985). Hunger and history: The impact of changing food production and consumption patterns on society. Cambridge: Cambridge University Press.

Taubenberger, J. K., \& Morens, D. M. (2006). 1918 Influenza: The mother of all pandemics. Emerging Infectious Diseases, 12(1), 15-22. doi: 10.3201/eid1209.050979

van Leeuwen, M. H. D., Maas, I., \& Miles, A. (2002). HISCO: Historical International Standard Classification of Occupations. Leuven: Leuven University Press.

5 Occupational titles were coded into HISCO using the dataset HSN standardized, HISCO-coded and classified occupational titles (2020). 